\title{
Non-specific arteritis of the aorta and its main branches
}

\author{
P. N. Thenabadu, K. Rajasuriya, and H. R. Wickremasinghe \\ From the University Medical Unit and Department of Pathology, \\ General Hospital, Colombo, Ceylon
}

Four cases of non-specific arteritis involving the aorta and its main branches are described. Three of the cases were hypertensive and one of these had evidence of aortic incompetence. Cases 1,2 , and 3 had involvement of the aortic arch vessels and the descending aorta, whereas Case 4 presented as a coarctation of the abdominal aorta. There was a significant association with systemic disturbance such as polyarthritis, fever, weight loss, raised erythrocyte sedimentation rate, and hyperglobulinaemia. A detailed necropsy in Case 2 showed two large dissecting aneurysms. The nomenclature, the diagnostic criteria, and a probable pathogenesis of the disease are discussed with reference to the relevant published material.

This paper is concerned with a disease mostly occurring in young women, involving the aorta and its main branches and having a welldefined natural history and pathological features. In 1908 Takayasu described peculiar ocular changes in a young woman under his care. It was Onishi (1908) who, however, showed that a patient with similar ocular changes had in addition absent radial pulses. Though no pathological studies were done, because of the occurrence of the disease in young Japanese women it is assumed that the cases described by Takayasu and Onishi were probably the first published ones of nonspecific arteritis.

The disease has been the subject of a large number of case reports and reviews under a variety of names such as 'reversed coarctation' (Giffin, 1939), 'the aortic arch syndrome' (Frøvig, 1946), 'pulseless disease' (Shimizu and Sano, I95I), 'young female arteritis' (Ross and McKusick, 1953), and 'obliterative brachio-cephalic arteritis' (Gibbons and King, 1957). The fact that the involvement of the aortic arch is not a hallmark of the disease was soon realized when cases were described with involvement of any part of the aorta and any of its main branches. Cases of aortitis affecting the descending aorta, described as 'elongate coarctation' (Milloy and Fell, 1959) and 'middle aortic syndrome' (Sen et al., 1963), which were thought to be distinct diseases, are probably a manifestation of the same disease entity. In

Received 9 April 1969. the search for a suitable term, 'pulseless disease' has too broad a connotation. Similarly, descriptive titles depending on the site of the aorta or vessels affected are of limited use. In the absence of any definite knowledge on the aetiology, the eponymous term 'Takayasu's disease' or a descriptive title of the pathology such as 'idiopathic or non-specific arteritis' should be used.

The purpose of this paper is to report 4 cases of Takayasu's arteritis admitted to the University Medical Unit, General Hospital, Colombo. These illustrate the diffuse nature of the aortic involvement and serve to emphasize the systemic nature of the disease and its close resemblance to the connective tissue disorders. In addition, the presence of dissecting aneurysms in the affected vessels in one of our cases is a feature not hitherto recorded.

Case I An unmarried 28-year-old woman was admitted with a history of effort dyspnoea of five years' duration. Her illness started in 1963 with a febrile episode lasting two weeks, followed a week later by swelling of the feet and dyspnoea. She was treated at hospital and left free of oedema. Since then she complained of loss of weight and of irregular attacks of fever lasting two to three weeks each. On her next admission to the unit three years later she was febrile, and had a diminution in the right radial, brachial, and subclavian pulsations. The blood pressures were $160 / 100 \mathrm{~mm}$. $\mathrm{Hg}$ in the right arm and $210 / 115 \mathrm{~mm} . \mathrm{Hg}$ in the left. There was cardiomegaly. Erythrocyte sedimentation rate was $60 \mathrm{~mm}$. in I hour. Blood cul- 
tures were repeatedly negative and muscle biopsy showed no evidence of polyarteritis nodosa.

A diagnosis of Takayasu's arteritis was made and she was treated with guanethidine and prednisolone.

On her next admission on 13 May 1968, she was anaemic. The pulsation in her right radial,

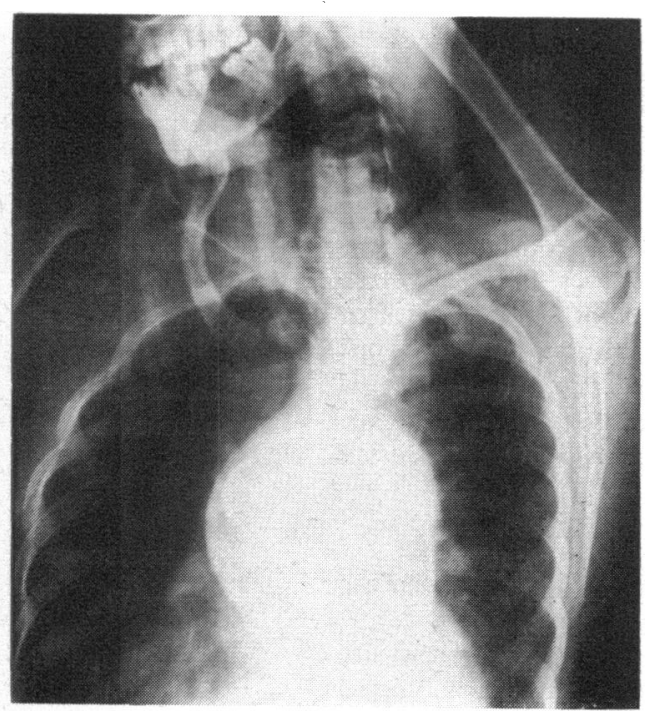

FIG. I Arch angiogram in Case I showing a slightly dilated aorta with obstruction of the right subclavian artery, and narrowing of both common carotid arteries for a variable distance from their origin.

FIG. 2 The descending aorta in Case I, showing a narrowed and irregular lumen.

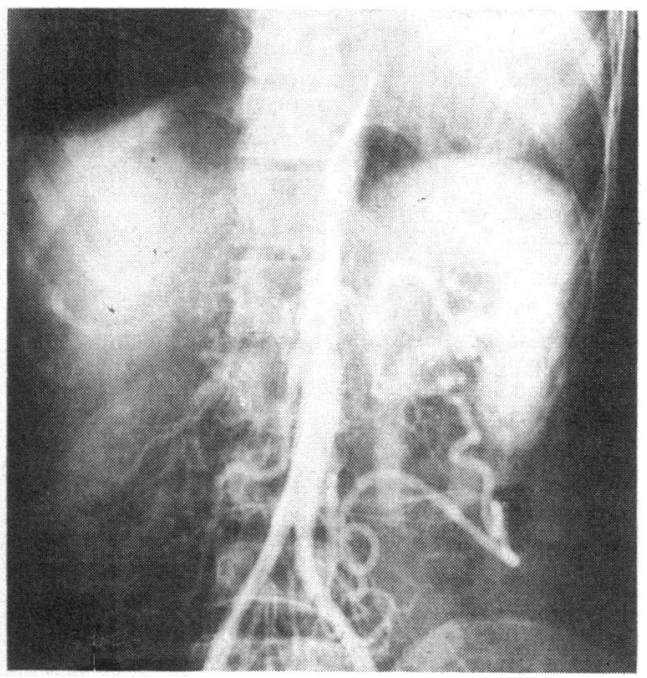

TABLE Results of investigations

\begin{tabular}{|c|c|c|c|c|}
\hline Investigation & Case I & Case 2 & Case 3 & Case 4 \\
\hline $\begin{array}{l}\text { Erythrocyte sedimentation rate } \\
\text { (Ist hour in mm.) } \\
\text { Haemoglobin (g./IO0 ml.) } \\
\text { Mantoux } \\
\text { Serological test for syphilis (VDRL) } \\
\text { Serum proteins (total g./I00 ml.) } \\
\text { Albumin } \\
\text { Globulin } \\
\text { Serum cholesterol (mg / I00 ml.) } \\
\text { Blood urea (mg./ I00 m.) } \\
\text { Blood culture } \\
\text { Latex flocculation test } \\
\text { Blood for lupus erythematosus cells } \\
\text { Antinuclear factor (fluorescent anti- } \\
\text { body technique) }\end{array}$ & $\begin{array}{c}55 \\
6 \cdot 4 \\
\text { Negative } \\
\text { Negative } \\
7 \cdot 4 \\
3 \cdot 7 \\
3 \cdot 7 \\
\text { I50 } \\
32 \\
\text { Negative } \\
\text { Negative } \\
\text { Negative } \\
\text { Negative }\end{array}$ & $\begin{array}{l}45 \\
6 \cdot 2 \\
\text { Positive } \\
\text { Negative } \\
7 \cdot 7 \\
3 \cdot 8 \\
3 \cdot 9 \\
\text { Not done } \\
\text { I6 } \\
\text { Negative } \\
\text { Negative } \\
\text { Negative } \\
\text { Negative }\end{array}$ & $\begin{array}{l}56 \\
6 \cdot 0 \\
\text { Positive } \\
\text { Not done } \\
7 \cdot 2 \\
3 \cdot 7 \\
3 \cdot 5 \\
\text { Not done } \\
22 \\
\text { Not done } \\
\text { Not done } \\
\text { Not done } \\
\text { Not done }\end{array}$ & $\begin{array}{l}25 \\
8 \cdot 6 \\
\text { Not done } \\
\text { Not done } \\
7 \cdot 3 \\
4 \cdot 6 \\
2 \cdot 7 \\
\text { Not done } \\
20 \\
\text { Not done } \\
\text { Negative } \\
\text { Negative } \\
\text { Not done }\end{array}$ \\
\hline
\end{tabular}

brachial, and subclavian arteries was diminished compared to the left. Both carotid pulsations were felt equally but the wall of the right felt irregular and beaded. The arterial pulsations in both lower limbs were weak. The blood pressure in the right arm was $140 / 110$, in the left arm 200/110, and in the thighs $170 / 120 \mathrm{~mm}$. $\mathrm{Hg}$. A systolic bruit was heard at the base of the neck on both sides and in the epigastrium. The apex beat was heaving and felt in the anterior axillary line in the seventh intercostal space. The heart sounds were normal and there was a soft ejection systolic murmur at the base and apex. The right optic fundus was anaemic compared to the left and digital ophthalmodynamometry revealed a low diastolic pressure in the right fundus as compared to the left.

Pathological investigations of the four cases are summarized in the Table. In Case I the chest film showed generalized cardiac enlargement and notching of the lower borders of the right third and fourth ribs. The electrocardiogram showed evidence of left ventricular hypertrophy and incomplete right bundle-branch block. An intravenous pyelogram showed that both kidneys excreted the contrast medium, but the concentration of the dye on the left was less than on the right side. Arch angiography and aortography (Fig. I) showed a dilated aortic arch. The right subclavian was obstructed distal to the origin of the right vertebral artery. The right and left common carotids were narrowed for a variable distance from their origin. The left subclavian was normal and the descending aorta showed a narrowed and irregular lumen (Fig. 2).

Case 2 A woman of 23 years was admitted to this unit on 3 October 1968, with a history of three months' effort dyspnoea and swelling of feet. At the age of 12 she had had arthritis of her left kuee lasting 2 weeks. This was not preceded by a sore throat. Since then she had had attacks of pain and stiffness of her finger joints for the next 2 years. She was treated for tuberculous cervical lymphadenitis (diagnosed by lymph node biopsy, two years ago) with INAH and PAS for about one year. Her menstrual history was irregular. She had been married for six years and had no children. 
On examination she was a thin frail anaemic woman with pitting oedema up to the thighs. She had lymphadenopathy of the cervical, axillary, and inguinal glands, and finger-clubbing on the right side. The right radial, brachial, and subclavian pulsation were diminished as compared to the left. The abdominal aortic pulsations were not felt. The femoral pulsations were diminished and delayed. The popliteal, dorsalis pedis, and posterior tibial pulsations were not felt. The blood pressure in the right arm was $80 / 50$, in the left arm 140/50, and in the thighs $110 / 60 \mathrm{~mm}$. $\mathrm{Hg}$. She was in congestive heart failure. There was cardiomegaly with biventricular enlargement. There was a proto-diastolic gallop rhythm heard in the left third space, a blowing early diastolic murmur in the aortic area and at the left sternal edge, with a soft ejection systolic murmur in the pulmonary area. Systolic bruits were also audible over the subclavian arteries in the supraclavicular fossae and to the left of the spine at about Dro. Her spleen was palpable one finger below the left costal margin.

\section{Investigations}

Chest $x$-ray showed generalized cardiomegaly with clear lung fields. Electrocardiogram showed left axis deviation, left ventricular hypertrophy, and $\mathrm{T}$ inversion in leads $\mathrm{VI}_{1}, \mathrm{~V}_{2}$, and $\mathrm{V}_{4}$. Aortography and cine-angiography showed a dilated ascending aorta, aortic incompetence with normal valvular mechanism, partial obstruction of right subclavian at its origin, and narrowing of right common carotid (Fig. 3). There was also narrowing of the descending abdominal aorta above the level of the renal arteries.

FIG. 3 Arch angiogram in Case 2, showing a dilated aorta, obstruction of the right subclavian artery at its origin, and narrowing of the right common carotid artery.

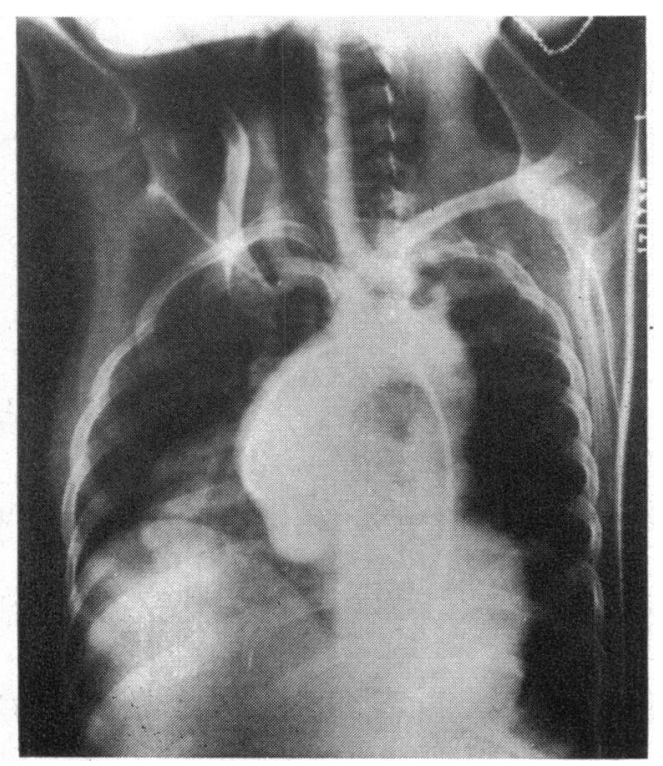

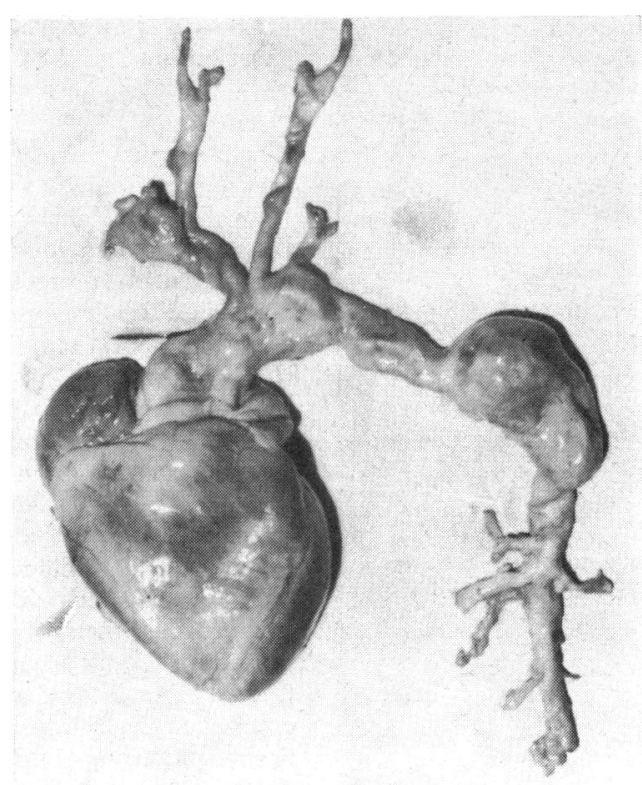

FIG. 4 Case 2. Irregular dilatation of the aorta with dissecting aneurysms in the descending aorta and right subclavian arteries.

FIG. 5 Case 2. The cut section of the dissecting aneurysm on the descending aorta showing blood clot and the laminated appearance of the fibrous capsule.

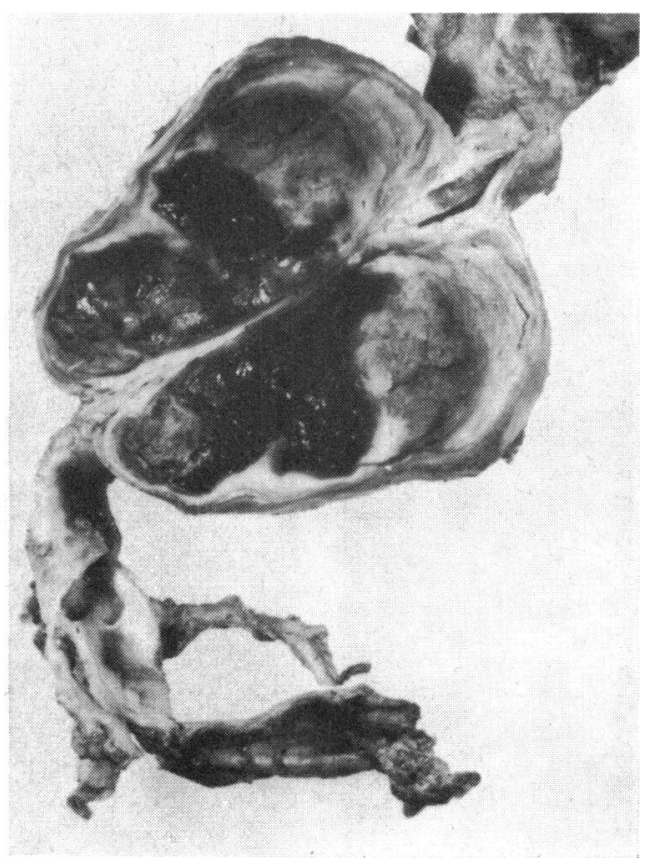


FIG.6 Case 2. Cut section of the aorta showing the irregular cobbled appearance of the intima. There is no communication with the dissecting aneurysm (arrow). The two openings seen are the ostia of two intercostal arteries.

FIG. 7 Case 2. Section from descending aorta showing medial fibrosis with fragmentation of elastic. Intimal and adventitial fibrosis is also prominent. (Elastic van Gieson. $\times 25$.)

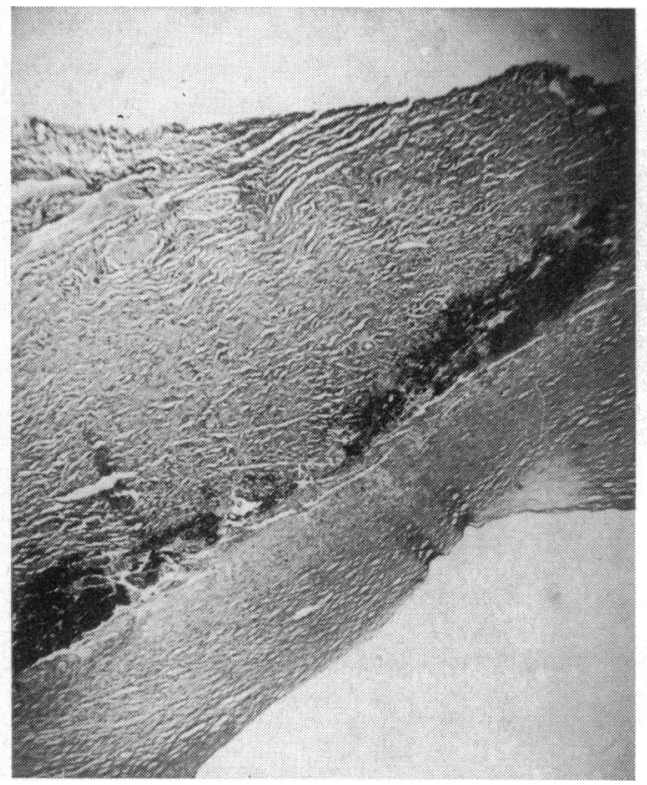

She was again readmitted in advanced congestive heart failure and died on 22 January 1969.

\section{Necropsy}

The heart was enlarged. The left ventricular wall was hypertrophied $(1.5 \mathrm{~cm}$.). The right ventricular wall, the atria, the atrioventricular valves, and the endocardium showed no abnormality.

The entire thoracic aorta starting from the valve ring was irregularly dilated (Fig. 4). A firm swelling about $3 \mathrm{~cm}$. in diameter was observed at the origin of the right subclavian. Sections of this showed laminated firm white tissue with soft yellow and brown material in the centre. A large swelling, ovoid, about $7 \mathrm{~cm}$. in length and about $4 \mathrm{~cm}$. in the largest diameter, was present in the thoracic aorta just above the diaphragm. This consisted of laminated white tissue with haematoma in the lower pole (Fig. 5). Both these masses reduced the lumen of the vessels to a thin slit but neither of them had any communication with the lumen. The intimal surface of the aorta had a cobbled appearance due to patchy fibrous or fleshy thickening (Fig. 6). No atheromatous changes of the endothelium were observed. The other arterial branches arising directly from the aorta were normal, as were the coronary and cerebral arteries.

FIG. 8 Case 2. Section from descending aorta, showing collection of lymphocytes and histiocytes in the media. (Haematoxylin and eosin. $\times$ 450.)

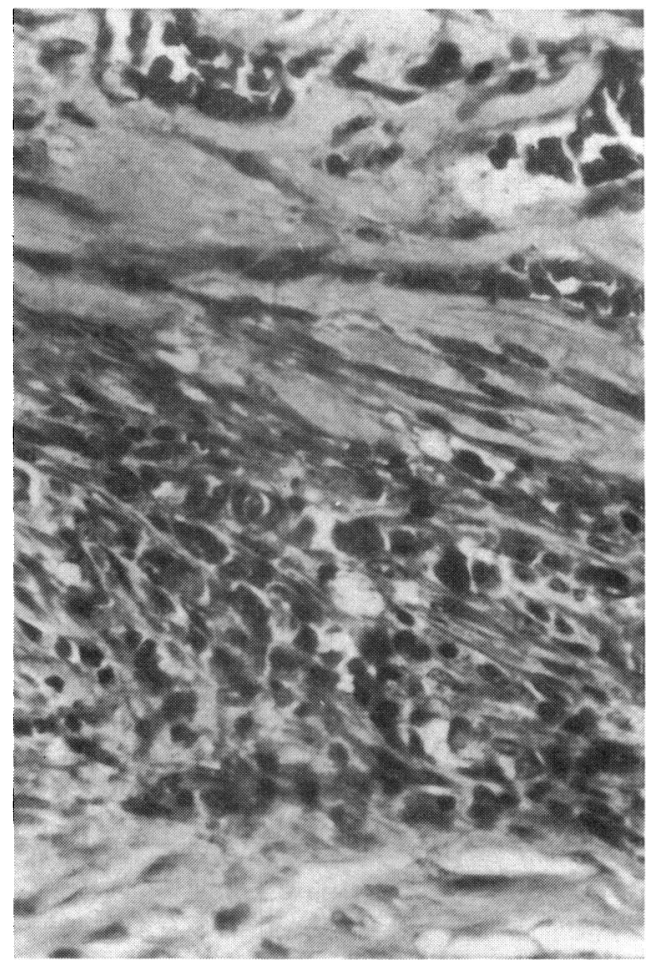


Histology Aorta: the intima was conspicuously thickened in some areas by fibrosis. The media was irregularly thinned and showed destruction or absence of elastic and muscle fibres with replacement fibrosis (Fig. 7). In some areas numerous vascular channels with perivascular chronic inflammatory cells were seen in the atrophic media (Fig. 8). The adventitia showed fibrous thickening and collection of chronic inflammatory cells around the vasa vasorum. There was no endarteritis of these vasa. No evidence of atheroma, cystic medial necrosis, or fibrinoid necrosis was seen in any of the sections examined.

The mass in the thoracic aorta was an organizing haematoma dissecting its wall. It consisted of a central zone of fibrin and red cells, a zone of granulation tissue with many chronic inflammatory cells outside this, and a peripheral zone of fibrous tissue. The histology of the mass in the right subclavian artery was similar, except for the presence of large collections of lipid-containing phagocytes in the wall. The other main branches of the aorta, the pulmonary artery and vein, and the coronary artery were histologically normal.

Heart: the left ventricle showed hypertrophic muscle fibres. The endocardium, pericardium, and interfascicular connective tissue were normal.

Case 3 A woman aged 29 years was admitted to this unit on 23 September 1968, with a history of intermittent claudication of the lower limbs of two weeks' duration. Her claudication distance was about ro yards and the pain was felt mainly in the calf muscle. One month previously she had fever with chills, and dysuria. In spite of treatment by a general practitioner she had continued to get the fever with chills about twice a week. She also gave a history of headache and pain in the small joints of her hands with stiffness, pain, and swelling of the left knee two years before. This subsided with Auyrvedic treatment. ${ }^{1}$ She was married, and had 6 children of whom 4 were living.

On examination she was a pale thin woman who had no webbing of the neck or increase in the carrying angle of the elbows. Both femoral pulses were weak and delayed. The popliteal and dorsalis pedis pulsations were not felt. The blood pressure in the right arm was $180 / 125$, in the left arm $130 / 100$, and in the thighs $130 / 1$ ro mm. $\mathrm{Hg}$. The heaving apex beat was in the fifth intercostal space $1.25 \mathrm{~cm}$. outside the midclavicular line. A soft ejection systolic murmur was followed by a loud aortic second sound. Ophthalmoscopy showed grade I hypertensive changes. $X$-rays of the chest and abdomen were normal. Electrocardiogram showed left ventricular hypertrophy and strain. The patient refused aortography.

Case 4 A girl aged 13 years was admitted to this unit from another hospital on 18 May 1967, with a history of joint swelling of one-and-a-half years' duration, and headache and effort dyspnoea for the previous one year.

1 The indigenous system of medicine in Ceylon.
On examination she was anaemic and febrile and showed generalized lymphadenopathy. There was no webbing of the neck or increased angle of the elbows. The pulsations of the peripheral arteries were normal and there was no femoral delay. The blood pressure in both arms was 220 / $160 \mathrm{~mm}$. Hg, and in the thighs $200 / 150 \mathrm{~mm}$. $\mathrm{Hg}$. A systolic murmur was heard in the abdomen, and to the right of the first lumbar vertebra posteriorly. The heart was not clinically enlarged. The left elbow joint was ankylosed at $45^{\circ}$ and inflamed. There was inflammatory swelling of the right ankle joint and spindling of the interphalangeal joints. The fundi showed grade I retinopathy.

The teleradiogram showed a slightly enlarged heart and widening of the ascending aorta. Electrocardiography showed left ventricular hypertrophy. A transfemoral aortogram showed coarctation of the aorta at the level of the renal arteries (Fig. 9).

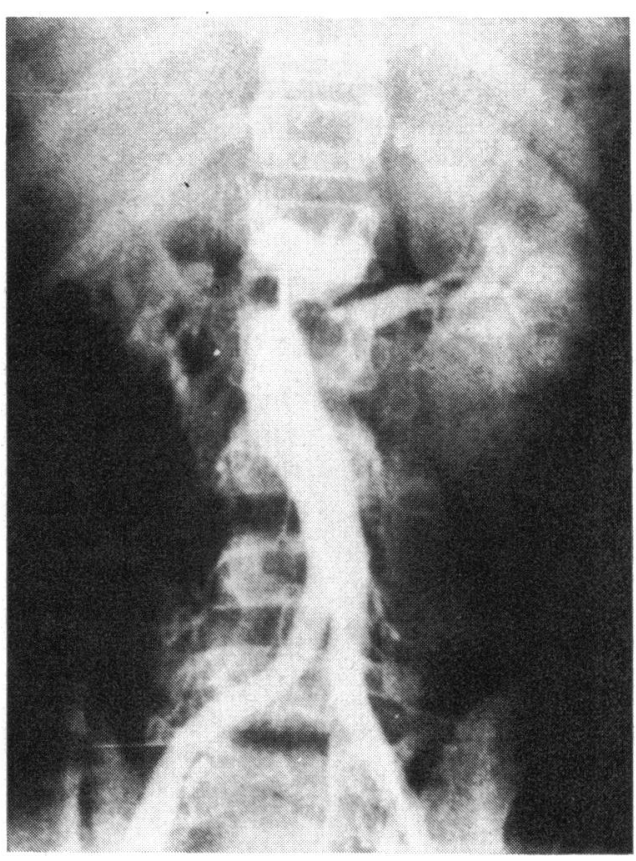

FIG 9 Aortogram in Case 4 showing narrowing of the descending aorta and non-opacification of the right renal artery.

At operation under moderate hypothermia there was a coarctation of the abdominal aorta at the level of the renal arteries, with adequate pulsations and flow distal to the coarctation. The right renal artery was very small with no pulsation. Left renal artery pulsation was good. A rightsided nephrectomy was done. The blood pressure dropped to $160 / 100 \mathrm{~mm}$. $\mathrm{Hg}$ soon after nephrectomy but later rose to $160 / 120 \mathrm{~mm}$. $\mathrm{Hg}$. 


\section{Discussion}

These four cases illustrate the protean clinical manifestations of Takayasu's disease. The characteristic features which help in the diagnosis of this condition are first, a strong predilection for affecting young women or girls. It is more prevalent in Asian and African countries than in the West (McKusick, 1962).

Secondly, apart from the arteritis, there is evidence of a systemic disturbance. The fact that this is essentially a generalized disease with a predilection for the aorta and its main branches was emphasized by Strachan (1964) in a review of the natural history of the disease. There is often irregular fever, fatigue, and weight loss, as seen in our Cases 1,2 , and 3. A history of arthritis was elicited in Cases 2, 3 , and 4. This was usually of a rheumatoid type but in all cases the flocculation tests were negative. Splenomegaly (Miller, Thomas, and Medd, 1962), and generalized lymphadenopathy have been rarely reported in this disease, and these were seen in Cases 2 and 4, respectively. All four patients in this series were anaemic and had a raised erythrocyte sedimentation rate. A hyperglobulinaemia was seen in Cases 1,2 , and 3, with a predominance of $\beta$ - and $\gamma$-globulins in Case 2 (Table).

Thirdly, there is involvement of the aorta and its main branches. This affection is variable and may involve any part of the aorta leading to obstruction by inflammatory narrowing or thrombosis, or it may lead to dilatation and aneurysm formation. Aortitis is diffuse, though in the early stage, when one vessel or one segment of the aorta is affected, it may be mistaken for a congenital anomaly. Cases 3 and 4, for example, presented a coarctation of the abdominal aorta and may have been mistaken for a congenital anomaly; this is, however, rare in female patients unless associated with Turner's syndrome. Moreover, Case 3 has involvement of the left subclavian artery and Case 4 of the right renal artery, and in both cases there was definite evidence of a systemic disturbance. The arterial involvement must also be distinguished from conditions such as atherosclerosis, syphilis, polyarteritis nodosa, giant cell arteritis, and dissecting aneurysm of the aorta. In the early and difficult cases, follow-up, or histological study if possible, usually discloses the true nature of the condition. The vessels affected may be suspected from the ischaemic symptoms, from reduced peripheral arterial pulsations, and from the different blood pressures found in the affected limbs. But the true extent of the involvement can only be determined by angiographic studies.
The fourth diagnostic criterion would be histological evidence obtained either by biopsy or at necropsy, but we must stress that a diagnosis cannot be made on such evidence alone. Biopsy is usually not possible owing to the segmental nature of the arterial involvement and the difficulty in obtaining suitable specimens. As pointed out by Judge et al. (1962), confusion can be avoided in the interpretation of the histopathology if one remembers the variability in the stage of the disease. Judge et al. (1962) conclude that the pathological process begins as a periarteritis and progresses to a panarteritis. Varying degrees of inflammation and repair would be seen in the various coats eventually leading to sclerosis. Our pathological findings in Case 2 are essentially in agreement with these observations, but we have not found evidence that there is a centripetal sequence of involvement. The extent of involvement of the three coats does not suggest such a sequence. We observed, for instance, gross intimal fibrosis and thickening, with minimal involvement of the media and adventitia. Nor are our observations consistent with the views of Judge et al. (1962) and Marquis et al. (1968) that the fibrosis and intimal thickening are secondary to the destructive changes in the media.

Cardiomegaly was seen in all our cases. The heart is involved in this disease either through hypertension, as in Cases I, 3, and 4, through aortic incompetence, as in Case 2, through obstruction of the coronary arteries at their ostia (Barker and Edwards, I955; Ross and McKusick, 1953), or through coronary arteritis (Danaraj, Wong, and Thomas, 1963). Hypertension is a common accompaniment of the disease and is usually due to renal artery narrowing or results from the coarctation of the aorta itself. Cardiac involvement or the development of hypertension are important events in the natural history of the disease, as their presence worsens the prognosis.

Case 2 was of interest because of the presence of two dissecting aneurysms, neither of which were shown on angiography; and the reason for this was apparent at necropsy where no communication with the parent vessel was seen. Though an intimal tear is not always shown, if absent the dissecting aneurysm is likely to be produced by destructive lesions of the medial vasa vasorum, producing an organized haematoma. The laminated structure of the wall of the dissecting haematoma also lends support to this view. While fusiform and saccular dilatations of the affected vessels have been described in Takayasu's 
disease, we have not come across a single published case of dissecting aneurysm in Takayasu's disease. In giant cell aortitis, where the histological appearance of the media can resemble that in Takayasu's disease, dissecting aneurysms are not uncommon (McMillan, 1950; Magarey, 1950; Paulley and Hughes, 1960; Harris, I968). The intimal fibrous thickening in giant cell aortitis is never so conspicuous as in Takayasu's disease, and this difference may be of significance in view of the rarity of dissecting aneurysms in Takayasu's disease.

The frequent association of this disease with tuberculosis has been observed earlier (Sen et al., 1963; Danaraj et al., 1963), but in Asian countries where there is a high incidence of tuberculosis such an association to be significant must have statistical support. Case 2 in the present series had been treated for tuberculosis of the cervical lymph nodes. Occasional cases with the features of Takayasu's disease and a positive lupus erythematosus cell test have been observed by Lessof and Glynn (1959), Judge et al. (1962), and Miller et al. (1962). However, these occasional cases with positive results are of little significance, as in most connective tissue disorders the lupus erythematosus cell phenomenon is more often negative. In fact, the lupus erythematosus cell test and the antinuclear factor have been negative in our cases. The association of overt rheumatoid arthritis with Takayasu's arteritis has been reported by Falicov and Cooney (1964) in a case of juvenile rheumatoid arthritis, and by Sandring and Welin (I96I) in three cases - two in adults and one with juvenile rheumatoid arthritis. Case 4 can be considered as another instance of the association of Takayasu's arteritis with Still's disease. However, the association of Takayasu's arteritis with transient arthritis and arthralgia (as in Cases 2 and 3) and other 'rheumatic' symptoms has been recorded more frequently (Ask-Upmark, 1954; Sandring and Welin, 196I ; Birke, Ejrup, and Olhagen, 1957; Strachan, 1964; Schrire and Asherson, 1964). Judge et al. (1962) suggest that this may be a connective tissue disorder with an auto-immunopathy affecting vascular elastin. However, most pathological studies, including the present one, indicate a more diffuse involvement of all the coats of the arterial wall than would be the case if elastin were primarily affected. Here we would again emphasize the dissociation of the intimal, medial, and adventitial changes. If an autoimmunopathy or other process primarily affecting a specific tissue element is to be invoked, the basophilic ground substance in which elastic, muscle, and collagen are all embedded appears more likely to be the target than elastin. It is significant that this basophilic ground substance is normally present in appreciable amounts in the aorta and the arteries affected in Takayasu's disease.

Our sincere thanks to Mr. A. T. S. Paul, General Hospital, Colombo, for operating on Case 4, to Dr. M. Weerasena and Dr. M. Jayasinghe for the arteriographic studies, and the Medical Superintendent, General Hospital, Colombo, for permission to publish.

\section{References}

Ask-Upmark, E. (1954). On the 'pulseless disease' outside of Japan. Acta Medica Scandinavica, 149, 16r.

Barker, N. W., and Edwards, J. E. (1955). Primary arteritis of the aortic arch. Circulation, II, 486.

Birke, G., Ejrup, B., and Olhagen, B. (1957). Pulseless disease; a clinical analysis of ten cases. Angiology, 8, 433.

Danaraj, T. J., Wong, H. O., and Thomas, M. A. (1963). Primary arteritis of the aorta causing renal artery stenosis and hypertension. British Heart fournal, 25, 153 .

Falicov, R. E., and Cooney, D. F. (1964). Takayasu's arteritis and rheumatoid arthritis. Archives of Internal Medicine, 114, 594.

Frøvig, A. G. (1946). Bilateral obliteration of the common carotid artery. Thromboangiitis obliterans? Acta Psychiatrica et Neurologica Scandinavica, Suppl. 39.

Gibbons, T. B., and King, R. L. (1957). Obliterative brachiocephalic arteritis: pulseless disease of Takayasu. Circulation, 15, 845.

Giffin, H. M. (1939). Reversed coarctation and vasomotor gradient: report of a cardiovascular anomaly with symptoms of brain tumour. Proceedings of the Staff Meetings of the Mayo Clinic, 14, 561.

Harris, M. (1968). Dissecting aneurysm of the aorta due to giant cell arteritis. British Heart fournal, 30, 840.

Judge, R. D., Currier, R. D., Gracie, W. A., and Figley, M. M. (1962). Takayasu's arteritis and the aortic arch syndrome. American fournal of Medicine, 32, 379.

Lessof, M. H., and Glynn, L. E. (1959). The pulseless syndrome. Lancet, I, 799.

McKusick, V. A. (1962). A form of vascular disease relatively frequent in the Orient. American Heart fournal, 63, 57.

McMillan, G. C. (1950). Diffuse granulomatous aortitis with giant cells, associated with partial rupture and dissection of the aorta. Archives of Pathology, 49, 63.

Magarey, F. R. (1950). Dissecting aneurysm due to giant-cell aortitis. Fournal of Pathology and Bacteriology, 62, 445 .

Marquis, Y., Richardson, J. B., Ritchie, A. C., and Wigle, E. D. (1968). Idiopathic medical aortopathy and arteriopathy. American fournal of Medicine, 44, 939.

Miller, G. A. H., Thomas, M. L., and Medd, W. E. (1962). Aortic arch syndrome and polymyositis with L.E. cells in peripheral blood. British Medical fournal, 1,771 .

Milloy, F., and Fell, E. H. (1959). Elongate coarctation of the aorta. Archives of Surgery, 78, 759.

Onishi (1908). Quoted by Takayasu, M. (1908). 
Paulley, J. W., and Hughes, J. P. (1960). Giant cell arteritis, or arteritis of the aged. British Medical fournal, 2, 1562.

Ross, R. S., and McKusick, V. A. (1963). Aortic arch syndromes. Diminished or absent pulses in arteries arising from arch of aorta. Archives of Internal Medicine, 92, 701.

Sandring, H., and Welin, G. (196I). Aortic arch syndrome with special reference to rheumatoid arthritis. Acta Medica Scandinavica, 170, I.

Schrire, V., and Asherson, R. A. (I964). Arteritis of the aorta and its major branches. Quarterly fournal of Medicine, 33, 439.
Sen, P. K., Kinare, S. G., Engineer, S. D., and Parulkar, G. B. (1963). The middle aortic syndrome. British Heart fournal, 25, 6 ro.

Shimizu, K., and Sano, K. (I95I). Pulseless disease. fournal of Neuropathology and Clinical Neurology, I, 37.

Strachan, R. W. (1964). The natural history of Takayasu's arteriopathy. Quarterly fournal of Medicine, 33, 57.

Takayasu, M. (I908). A case with peculiar changes of the central retinal vessels. Acta Societatis Ophthalmologicae faponicae, 12, 554. 